\title{
Bone Remodeling after Ulna Head Replacement in Distal Radioulnar Joint Arthroplasty: A Radiographic Comparison between a Partial and a Total Ulna Head Concept
}

\author{
Elisabeth Brogren, $\mathrm{MD}, \mathrm{PhD}^{1,2(0)}$ Antonio Abramo, $\mathrm{MD}, \mathrm{PhD}^{1,2}$ Magnus Tägil, $\mathrm{MD}, \mathrm{PhD}^{3,4}$ \\ ${ }^{1}$ Department of Hand Surgery, Skåne University Hospital, Malmö, \\ Sweden \\ 2 Department of Translational Medicine, Lund University, Lund, Sweden \\ 3 Department of Orthopedics, Skåne University Hospital, Malmö, Sweden \\ Address for correspondence Elisabeth Brogren, MD, PhD, \\ Department of Hand Surgery, Skåne University Hospital, Jan \\ Valdenströms gata 5, 20502 Malmö, Sweden \\ ${ }^{4}$ Department of Clinical Sciences, Lund University, Lund, Sweden \\ (e-mail: elisabeth.brogren@med.lu.se).
}

J Wrist Surg 2022;11:425-432.

\begin{abstract}
Background Ulna head arthroplasty has become an eligible solution for injury or disease in the distal radioulnar joint. Bone resorption beneath the prosthetic head is often reported, but mechanism poorly understood.

Purpose The aims were to evaluate bone remodeling and radiological instability in two conceptually different distal radioulnar joint arthroplasties: the total and the partial ulna head replacement.

Patients and Methods We conducted a retrospective radiographic assessment of 51 ulna head arthroplasties; 26 Herbert ulna (total ulna head replacement) and 25 First Choice (partial ulna head replacement), to analyze periprosthetic bone resorption and radiologic instability. Intraoperative/immediate postoperative and 1-year radiographs were reviewed by two independent assessors. The radiographic follow-up averaged 13 $(10-17)$ months. The size of the stem in relation to the diameter of the ulna (filling ratio) was measured on the intraoperative/immediate postoperative radiographs. Bone resorption beneath the collar of the prothesis was measured on the 1-year radiographs and expressed as a bone resorption index (BRI) between the length of the resorption and the length of the implant stem. Radiological stability was measured on both the preoperative and the 1-year lateral radiographs.

Keywords

- ulna head arthroplasty

- distal radioulnar joint

- bone resorption

- stress shielding

Results The total ulna head prothesis presented with more extensive bone resorption beneath the prosthetic head than the partial ulna head prothesis at 1-year post surgery $(p<0.001)$. The filling ratio did not influence the 1-year bone resorption and there was no difference regarding radiological instability between the two prosthetic designs. Conclusion The pattern of bone adaptions after an ulna head prothesis may differ due to design and concept of the prosthesis.
\end{abstract}

received

October 5, 2021

accepted

November 17, 2021

published online

January 20, 2022
DOI https://doi.org/

10.1055/s-0041-1742098. ISSN 2163-3916.

\footnotetext{
(C) 2022. The Author(s).

This is an open access article published by Thieme under the terms of the Creative Commons Attribution-NonDerivative-NonCommercial-License, permitting copying and reproduction so long as the original work is given appropriate credit. Contents may not be used for commercial purposes, or adapted, remixed, transformed or built upon. (https://creativecommons.org/ licenses/by-nc-nd/4.0/)

Thieme Medical Publishers, Inc., 333 Seventh Avenue, 18th Floor, New York, NY 10001, USA
} 
Ulna head arthroplasty for reconstruction of painful disorders of the distal radioulnar joint (DRUJ) has become increasingly popular over the last two decades as an alternative to simple ulnar head resection or the Kapandji-Sauvé procedure. ${ }^{1}$ The clinical reports are few and the outcome of the various implants are mostly based on small, retrospective case series. ${ }^{1-8}$ Most series report improved function, effective pain relief and preserved forearm rotation in most patients, and an implant survival of 90 to $100 \% 5$ years postoperatively. ${ }^{1,9}$ Radiographic phenomena, such as periprosthetic bone resorption and implant subluxation are frequently being described. ${ }^{9}$

In total joint DRUJ arthroplasty, both the ulna head and the radius fossa are replaced and the joint stability is provided by the implant itself. ${ }^{10}$ As a contrast, in the hemi joint DRUJ arthroplasty, or simply the ulna head arthroplasty, only the ulnar head is replaced, partially or totally, allowing the prosthetic head to articulate against the non-replaced sigmoid notch. ${ }^{10}$ The joint stability in ulna head replacements is provided by the joint surface congruity together with the native primary and secondary, static and dynamic stabilizers. The partial ulna head replacement was introduced to preserve the osseous origins of the primary static distal radioulnar joint (DRUJ stabilizers, i.e., the radioulnar and the ulnocarpal ligaments) and the insertion of the triangular fibrocartilage complex. ${ }^{11,12}$ The ulnar side of the distal ulna, with its ligament insertions, thus remains, in contrast to the total ulna head replacement in which the whole head is resected and replaced. ${ }^{13}$ The joint stability in total ulna head replacements therefore depends on the reconstructed and reinforced joint capsule, including the remaining static secondary stabilizers like the interosseous membrane with the distal oblique band, and the dynamic secondary stabilizers like the pronator quadratus and the extensor carpi ulnaris. ${ }^{14}$ For both the partial and total head replacement concepts, the joint architecture and congruity are important for both stability and motion, both immediately after implantation and at long term. $^{15}$

Any implant inserted into the medullary canal of a long bone changes the distribution of load, which in turn causes alterations in the structural properties of the bone, according to Wolff's law. ${ }^{16,17}$ Both an increased as well as a decreased load may lead to bone resorption. ${ }^{18}$ The phenomenon of stress shielding after joint implantation has been widely studied in hip and shoulder arthroplasty, but little is known about periprosthetic bone remodeling in ulna head arthroplasties. $^{9,17,19-21}$

The purpose of this study was to describe and compare early bone remodeling in two conceptually different ulna head arthroplasties, the partial and the total ulna head replacement. Our primary aim was to investigate signs of bone resorption of the distal ulna within the first year postoperatively and whether we could identify any factors that influence bone resorption. We also aimed to evaluate and compare signs of radiological instability between the total and partial ulna head replacement.

\section{Methods}

\section{Patients}

We conducted a retrospective study analyzing the early radiographic appearance of wrists treated with a partial or total ulna head replacement at the Department of Hand Surgery in Malmö, and the Department of Orthopedic Surgery in Lund, both at the Skane University Hospital in Sweden. The patients were operated over a 13-year period (January 2006 to March 2019).

Information on demographics, diagnosis, indications for surgery, surgical technique, simultaneous surgery, and complications were taken from prospective registers as well as from the medical records. All patients were included, if aged 18 or older, treated with either a partial ulna head replacement (First Choice) or a total ulna head replacement (Herbert ulna head) for any diagnosis, and with both the intraoperative/immediate postoperative and the 1-year radiographs available.

In total, 60 wrists in 59 patients (28 partial ulna head and 32 total ulna head replacements) were operated during the study period. Three patients were excluded because of revision surgery within 6 months (-Fig. 1). Another six patients were excluded due to missing intraoperative/ immediate postoperative or 1-year follow-up radiograms. The final cohort, thus, consisted of 50 patients ( 51 wrists; 25 partial ulna head, and 26 total ulna head replacements).

\section{Implant Designs}

The First Choice Partial Ulnar Head Replacement (Integra LifeSciences, NJ) is a non-constrained, single component, cobalt-chrome ( $\mathrm{CoCr}$ ), partial ulna head prosthesis with a grit blasted stem. The prosthesis is available in four head sizes and in three stem diameters. The operations were performed as described by Kopylov and Tägil, ${ }^{11}$ with a press-fit technique, and without bone grafting. No stems were cemented.

The Herbert ulna head prothesis (Martin Medizin Technik, Tuttlingen, Germany) is a non-constrained, modular, total ulna head prosthesis with a titanium-coated stem and a ceramic head. The head is available in three sizes and fits any of the nine stem sizes (three different diameters and three different collar lengths). The operations were performed as described by van Schoonhoven et al and Herbert et al. ${ }^{13,22} \mathrm{~A}$ press-fit technique was used in 22 patients. In three patients (four wrists) the stem was cemented because of poor bone stock. No bone graft was used, and all stems were standard (no extended collar).

One of the patients that received a Herbert ulna head prosthesis had previously undergone the Kapandji-Sauvé procedure, but no other patients had had previous surgery on the DRUJ.

\section{Radiographic Evaluation}

Anteroposterior and lateral radiographs were made of the distal radius and ulna, preoperatively, intraoperatively/immediate postoperatively and after 1 year. Two senior hand surgeons independently examined all radiographs, and all 


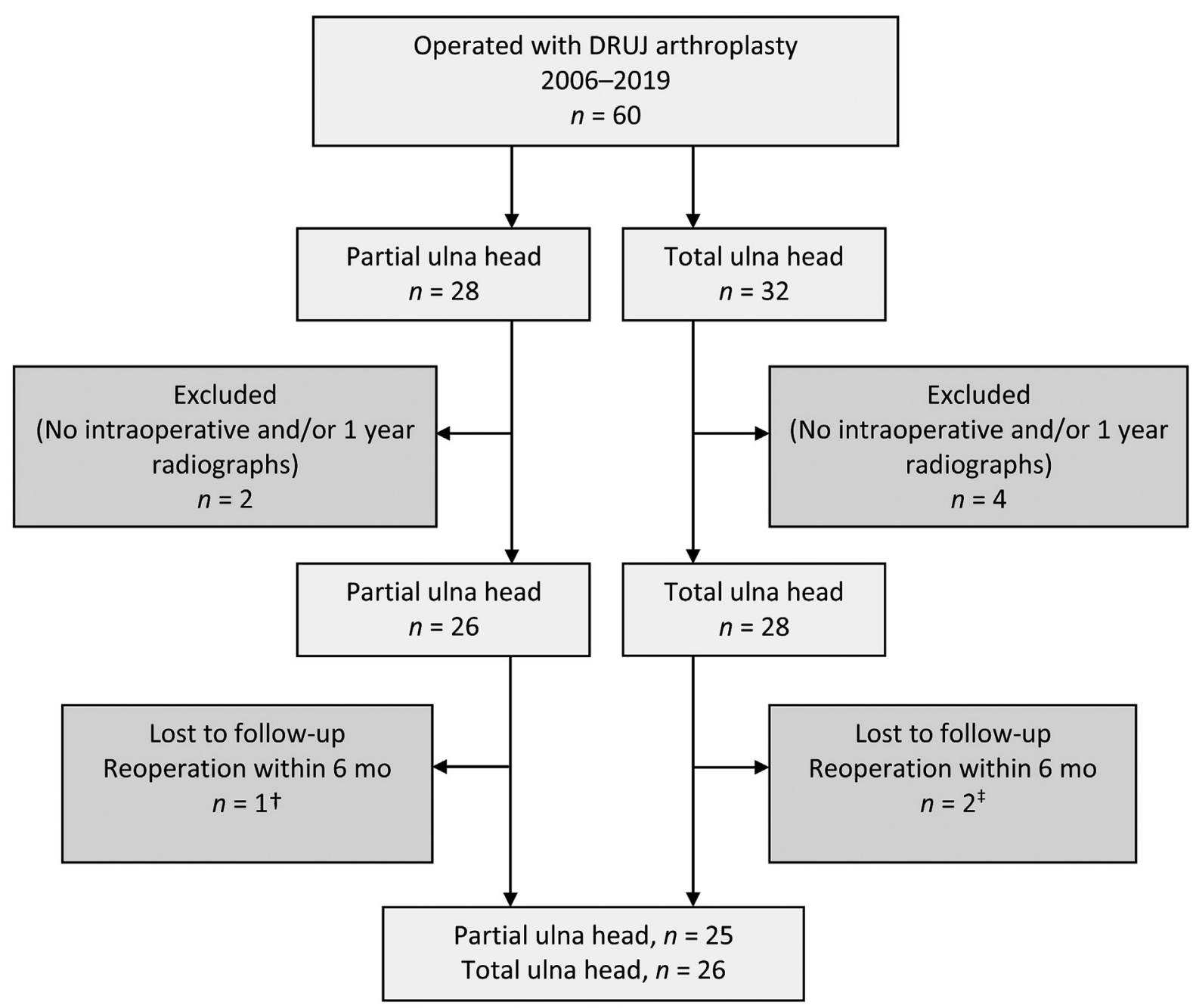

Fig. 1 Flowchart of included wrists. ${ }^{\dagger}$ One patient was reoperated because of septic loosening of the implant (revision). DRUJ; distal radioulnar joint. ${ }^{\ddagger}$ One patient was reoperated because of aseptic loosening of the implant (revision) and one patient was reoperated because of undefined pain (converted to ulnar head resection).

measurements were performed on digital radiographs (SectraPACS IDS7).

The filling ratio of the prosthesis was calculated as previously described in shoulder arthroplasties. ${ }^{21}$ The diameter of the inner ulna cortex and the prosthesis was measured, (1) beneath the collar, (2) at the middle, and (3) at the tip of the prothesis, on the anteroposterior view of the intraoperative/ immediate postoperative radiographs. The filling ratio was calculated using the diameter of the prothesis divided by the diameter of the inner cortex ( $\mathbf{- F i g . ~ 2 A ) . ~}$

The bone resorption index (BRI) was calculated as described by Herzberg. ${ }^{23}$ The cortical bone resorption proximal to the ulnar head, was measured in millimeters $(\mathrm{mm})$ both at the ulnar and radial border, on the anteroposterior 1-year radiographs. A ratio was calculated between the length of the periprosthetic bone resorption and the length of the stem of the prothesis (mm) (-Fig. 2B).

The 1-year bone resorption was further classified into three classes according to Herzberg, minimal, average, and maximum bone resorption. ${ }^{23}$
The presence of radiological DRUJ instability was measured on the lateral radiographs, both at the preoperative and the 1-year follow-up radiographs as described by Kakar et al. ${ }^{3}$ Two longitudinal lines at the center of the radius and the ulna head were drawn and the distance between the lines measured at the level of the sigmoid notch $(-$ Fig. $2 \mathbf{C})$. A positive difference greater than $5 \mathrm{~mm}$ between the lines has been defined as dorsal instability and a negative difference greater than $5 \mathrm{~mm}$ as volar instability. ${ }^{3}$

\section{Statistics}

Parametric data are shown as means and SD, and nonparametric as medians, quartiles, or proportions as appropriate. The inter-rater agreement between the two independent assessors was calculated using the intraclass correlation coefficient for each radiological measurement. Mann-Whitney U-test or Chi-square test was performed depending on variable, to analyze the differences in patient characteristics and to compare the two prosthetic designs regarding filling ratio, bone resorption, BRI, and radiological stability. Stem 
A

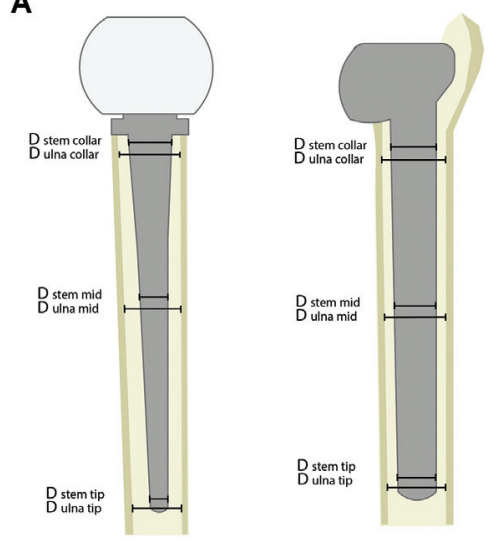

B

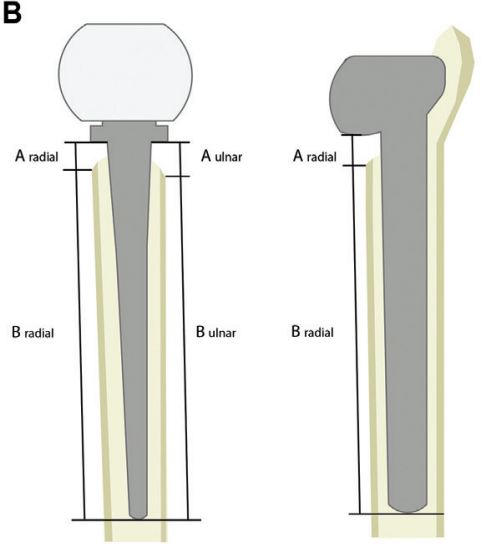

C

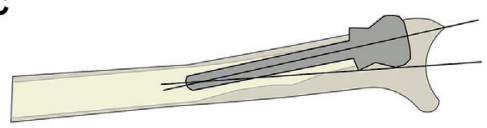

Fig. 2 Schematic drawing of radiological measurements. (A) filling ratio at the collar, mid stem, and at the tip of the prothesis at intraoperative/immediate postoperative radiographs, (B) bone resorption at the radial and/or ulnar border of the prothesis at the 1 year radiographs, and $(\mathrm{C})$ radiologic instability, measured on preoperative and 1-year radiographs.

length was tested using the Student's $t$-test and preoperative and 1-year radiological instability using the MacNemar test. To investigate any relationship between the intraoperative/ immediate postoperative filling ratio and BRI and between radiological instability at 1 year and BRI, we used one-way analyses of covariance (ANCOVA), adjusting for diagnosis, sex, and prosthetic design.

\section{Results}

\section{Patient Characteristics}

The partial ulna head prosthesis was more commonly used in women $(p=0.03)$ and in patients with RA $(p=0.003)$. Concomitant procedures were more common in patients with inflammatory arthritis (16 procedures) than in patients with OA (six procedures) $(p=0.007)$. Patient characteristics are presented in -Table $\mathbf{1}$.
Table 1 Patient characteristics

\begin{tabular}{|c|c|c|c|}
\hline & All & $\begin{array}{l}\text { Partial ulna } \\
\text { head }\end{array}$ & $\begin{array}{l}\text { Total ulna } \\
\text { head }\end{array}$ \\
\hline $\begin{array}{l}\text { No. of patients } \\
\text { (wrists) }\end{array}$ & $50(51)$ & $25(25)$ & $25(26)$ \\
\hline Men & $15(16)$ & $4(4)$ & $11(12)$ \\
\hline Women & $35(35)$ & $21(21)$ & $14(14)$ \\
\hline \multicolumn{4}{|l|}{ Operated side $(n)$} \\
\hline Right & 30 & 16 & 14 \\
\hline Left & 19 & 9 & 10 \\
\hline Bilateral & 1 & 0 & 1 \\
\hline $\begin{array}{l}\text { Age at surgery, } \\
\text { mean (range) } \\
\text { years }\end{array}$ & $60(22-80)$ & $57(22-72)$ & $62(38-80)$ \\
\hline $\begin{array}{l}\text { Follow-up length, } \\
\text { mean (range) } \\
\text { months }\end{array}$ & $13(10--17)$ & $13(11-17)$ & $13(10-16)$ \\
\hline \multicolumn{4}{|l|}{$\begin{array}{l}\text { Indications for } \\
\text { surgery }(n)\end{array}$} \\
\hline $\mathrm{OA}$ & 23 & 6 & 17 \\
\hline RA & 27 & 19 & 8 \\
\hline PSA & 1 & 0 & 1 \\
\hline \multicolumn{4}{|l|}{$\begin{array}{l}\text { Simultaneous } \\
\text { surgery }\end{array}$} \\
\hline $\begin{array}{l}\text { Tendon } \\
\text { reconstruction }\end{array}$ & 4 & 0 & 4 \\
\hline $\begin{array}{l}\text { Partial wrist } \\
\text { fusion (PWF) }\end{array}$ & 9 & 4 & 5 \\
\hline $\begin{array}{r}\text { Total wrist } \\
\text { fusion (TWF) }\end{array}$ & 10 & 8 & 2 \\
\hline $\begin{array}{l}\quad \text { PWF and } \\
\text { tendon } \\
\text { reconstruction }\end{array}$ & 1 & 0 & 1 \\
\hline
\end{tabular}

Abbreviations: OA, osteoarthritis; PSA, psoriasis arthritis; RA, rheumatoid arthritis.

\section{Non-Respondents}

The nine patients that were excluded did not differ from the included patients in terms of diagnosis $(p=0.34)$, sex $(p=0.59)$, or age at surgery $(p=0.6)$.

\section{Radiographic Evaluation of Bone Resorption}

The intraoperative/immediate postoperative filling ratio differed significantly between the partial and total ulna head replacements, with a larger filling ratio beneath the collar in the total and a larger filling ratio at the middle and tip of the stem in the partial ulna head replacement (-Table $\mathbf{2}$ ).

In the total ulna head replacement, the median length of the bone resorption zone immediately proximal to the implant head at 1 year, as well as the BRI, was larger at the radial border as compared to the partial $(p<0.001)$ (-Table 2). The stem length did not differ between the total (mean 55 [SD 1.5] $\mathrm{mm}$ ) and the partial ulna head prothesis (mean 55 [SD 2.3] $\mathrm{mm}, p=0.9$ ). Bone 
Table 2 Intraoperative/immediate postoperative filling ratio, 1-year bone resorption in millimeters (mm), 1-year bone resorption index (BRI) and 1-year bone resorption classified according to Herzberg in partial ulna head and total ulna head arthroplasties

\begin{tabular}{|l|l|l|l|}
\hline & Partial ulna head & Total ulna head & $p$-Value \\
\hline Filling ratio & & & \\
\hline Collar & $0.65(0.59-0.71)$ & $0.79(0.72-0.87)$ & $<0.001$ \\
\hline Mid stem & $0.85(0.76-0.89)$ & $0.54(0.44-0.69)$ & $<0.001$ \\
\hline Tip & $0.87(0.72-0.91)$ & $0.41(0.34-0.5)$ & $<0.001$ \\
\hline Bone resorption, mm & & & \\
\hline Radial & $2.6(0.43-4.2)$ & $6.0(4.3-7.8)$ & $<0.001$ \\
\hline Ulnar & NA & $4.3(3.1-5.8)$ & NA \\
\hline BRI & & & \\
\hline Radial & $0.05(0.01-0.08)$ & $0.11(0.08-0.14)$ & $<0.001$ \\
\hline Ulnar & NA & $0.07(0.06-0.11)$ & NA \\
\hline Herzberg classification & & & \\
\hline Minimal, $n$ (\%) & $19(76)$ & $4(15)$ & \\
\hline Average, $n$ (\%) & $4(16)$ & $18(70)$ & $<0.001$ \\
\hline Maximum, $n$ (\%) & $2(8)$ & $4(15)$ & \\
\hline
\end{tabular}

Abbreviation: BRI, bone resorption index.

Note: Values presented as median (IQR, interquartile range) or numbers and percentages.

resorption was more pronounced in the total than in the partial ulna head replacement at the 1-year radiographs (-Table 2; -Fig. 3). The intraoperative/immediate postoperative filling ratio did not affect the 1-year radial BRI, as analyzed by one-way ANCOVA adjusted for diagnosis, sex, and prosthesis design, filling ratio collar $(p=0.36)$, mid $(p=0.35)$, and tip $(p=0.38)$.

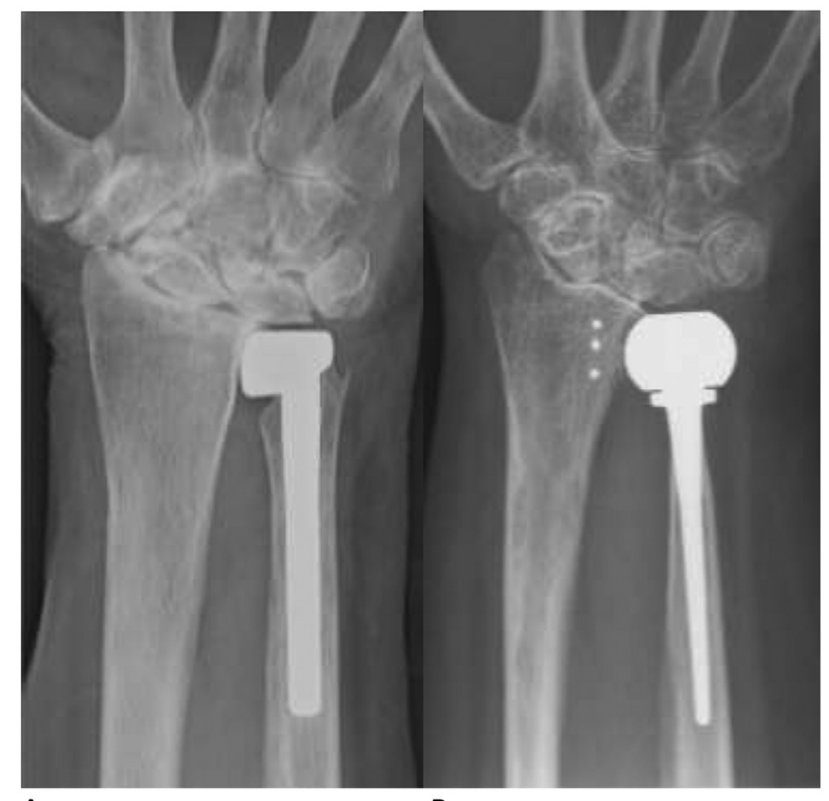

A

B

Fig. 3 Radiographs 1 year after ulna head replacement with bone resorption beneath the ulnar head in (A) partial ulna head and (B) total ulna head in two female patients with rheumatoid arthritis.

\section{Radiographic Evaluation of Radiological Instability}

In wrists that received the total ulna head replacement, seven (27\%) wrists had preoperative dorsal instability ( $>5 \mathrm{~mm}$ ), and 10 wrists (39\%) had evidence of dorsal instability at 1 year $(p=0.72)$. In wrists that received the partial ulna head replacement, four (16\%) had dorsal instability at the preoperative examination, and nine (36\%) had dorsal instability at 1 year $(p=0.25)$.

In the total ulna head replacement group, four of the seven patients with radiological signs of preoperative dorsal DRUJ instability still had dorsal implant instability after 1 year, whereas all four patients with preoperative dorsal joint instability presented with dorsal instability 1 year after a partial ulna head replacement. There was no difference in preoperative DRUJ dorsal instability or 1-year implant dorsal instability between the two prosthetic designs (-Table 3 ). No relationship was found between radiological stability and radial BRI at 1 year, by one-way ANCOVA $(p=0.25)$ adjusted for diagnosis, sex, and prothesis design.

\section{Inter-rater Reliability}

The inter-rater agreement between the two assessors was good to excellent, except for bone resorption on the ulnar side of the prothesis, for which it was moderate ( - Table 4).

\section{Complications}

Intraoperative fracture of the ulna shaft (three patients with total ulna head replacement) and the ulna styloid (two patients with partial ulna head replacement) was recorded. One patient with a partial ulna head replacement was reoperated after 6 months with a capsular reinforcement due to DRUJ instability. 
Table 3 Preoperative radiological DRU] instability and 1-year implant instability in the partial and total ulna head arthroplasties

\begin{tabular}{|c|l|l|l|}
\hline & Partial ulna head & Total ulna head & $p$-Value \\
\hline Radiological instability, median (IQR) & & & \\
\hline Preop (mm) & $2.6(1.3-3.8)$ & $3.7(2.0-5.6)$ & 0.16 \\
\hline 1 y $(\mathrm{mm})$ & $4.0(2.2-5.7)$ & $4.0(2.2-8.8)$ & 0.42 \\
\hline Dorsal instability preop ${ }^{\mathrm{a}}$ & & & \\
\hline$>5 \mathrm{~mm}, n(\%)$ & $4(16)$ & $7(27)$ & 0.48 \\
\hline$<5 \mathrm{~mm}, n(\%)$ & $17(68)$ & $17(65)$ & \\
\hline Dorsal instability 1 y & & & 0.86 \\
\hline$>5 \mathrm{~mm}, n(\%)$ & $9(36)$ & $10(39)$ & \\
\hline$<5 \mathrm{~mm}, n(\%)$ & $16(64)$ & $16(61)$ & \\
\hline
\end{tabular}

Abbreviation: IQR, interquartile range.

aPreoperative data missing for four wrists with partial ulna head and two patients with total ulna head.

Table 4 Inter-rater agreement between the two blinded assessors

\begin{tabular}{|l|l|l|l|l|}
\hline & Assessor 1 mean (SD) & Assessor 2 mean (SD) & ICC & $95 \%$ Cl \\
\hline Filling ratio collar & $0.77(0.15)$ & $0.72(0.16)$ & 0.69 & $0.44-0.82$ \\
\hline Filling ratio mid & $0.74(0.16)$ & $0.68(0.18)$ & 0.89 & $0.74-0.95$ \\
\hline Filling ratio tip & $0.70(0.22)$ & $0.64(0.23)$ & 0.88 & $0.77-0.94$ \\
\hline Bone resorption, radial side (mm) & $3.4(2.7)$ & $4.3(2.7)$ & 0.89 & $0.71-0.95$ \\
\hline Stem length (mm) & $55(2.0)$ & $55(1.9)$ & 0.97 & $0.95-0.98$ \\
\hline Bone resorption, ulnar side (mm) & $4.4(3.3)$ & $4.6(2.3)$ & 0.54 & -0.40 to 0.78 \\
\hline Radiological instability 1 y & $5.3(3.3)$ & $4.9(3.3)$ & 0.89 & $0.80-0.94$ \\
\hline
\end{tabular}

Abbreviations: $\mathrm{Cl}$, confidence; ICC, intra-class correlation; SD, standard deviation.

\section{Discussion}

Periprosthetic bone resorption and radiological instability after ulna head replacements have been described in the literature. ${ }^{3,5,6,8,9}$ To further explore these phenomena, we compared two different prosthetic concepts: the total and partial ulna head replacements.

Our study has limitations. The intraoperative/immediate postoperative radiographs were not performed in standardized setting, which could have interfered with our measurements. However, the inter-rater agreement of the radiographic measurements was acceptable. We did not use validated methods for measurements since these are lacking. Finally, the two groups of patients that received a total versus a partial ulna head replacement differed in sex, underlying diagnosis, and the rate of simultaneous additional procedures performed.

In the present study we found that bone resorption beneath the ulnar collar, immediately proximal to the replaced ulnar head, was more pronounced 1 year after the total ulna head than after the partial ulna head replacement. Similar to our study, a tendency to less bone resorption proximal to the prosthetic ulna head was reported in the partial compared to the total head replacements in one small retrospective study of 28 patients ( 10 total and 18 partial First Choice). ${ }^{24}$ Resorption of bone beneath the prosthetic head in general is considered unwanted, since long-term implant fixation depends on the preservation of local bone stock. ${ }^{19}$ Although the consequences in ulna head replacements remain unclear, many surgeons prefer to preserve as much bone stock as possible, considering the risk of periprosthetic fracture and difficulties if implant revision would later be necessary. Our findings raise the question as to why bone resorption seems to be more pronounced after total than partial ulna head replacements.

A number of patient- and implant-related factors can influence bone remodeling, most probably acting together as a combination of mechanisms. Some stress shielding can be expected after successful arthroplasty since the load of the native bone is altered. The extent of bone resorption and the location at which it occurs, vary with the prosthetic design, stiffness, and size. ${ }^{19-21}$ In shoulder arthroplasty, stress shielding can be reduced using a short humeral stem or stemless design, as compared with a standard stem. ${ }^{20} \mathrm{~A}$ larger stem size relative to the diameter of the diaphyseal bone (i.e., larger filling ratio) also increases the risk of proximal stress shielding in shoulder arthroplasties. ${ }^{21}$ In hips, proximal femoral stress shielding is more common using uncemented fixation, in particular in distally anchored prostheses. ${ }^{25}$ In ulna head arthroplasties, the First Choice and Herbert ulna head arthroplasties differ in both concept and design, giving multiple possible explanations to our findings (-Table 5). Ulna head arthroplasties resemble shoulder arthroplasties in the sense 
Table 5 Differences in concept and design between the Herbert ulna head and the First Choice arthroplasties

\begin{tabular}{|c|l|l|}
\hline Concept & First Choice & Herbert ulna head \\
\hline Stability & $\begin{array}{l}\text { Capsule, primary } \\
\text { stabilizers } \\
\text { and secondary } \\
\text { stabilizers }\end{array}$ & $\begin{array}{l}\text { Capsule } \\
\text { and secondary } \\
\text { stabilizers }\end{array}$ \\
\hline Modular & No & Yes \\
\hline Stem & Grit blasted & Titanium \\
\hline Alloy & Rounded & Tapered \\
\hline Shape & No & Yes \\
\hline Collar & Cobalt-chrome & Ceramic \\
\hline Head & Anatomical & Spherical \\
\hline Material & Shape &
\end{tabular}

aPrimary stabilizers; the radioulnar and the ulnocarpal ligaments and the insertion of the triangular fibrocartilage complex (TFCC).

bSecondary stabilizers; the interosseous membrane with the distal oblique band, the pronator quadratus and the extensor carpi ulnaris.

that a wide stem is inserted into a long bone with a relatively small diameter. The shape of the Hebert ulna stem is tapered, with a larger filling ratio at the collar, whereas the First Choice has a non-tapered stem, with a larger filling ratio at the middle and tip of the implant compared to the Herbert ulna. We could not demonstrate that a larger filling ratio at the collar, mid stem, or tip of the prothesis at the time of surgery was associated with higher risk of developing stress shielding or bone resorption at 1 year.

Although common, bone resorption secondary to stress shielding seems to stabilize within the first year, and most reports on hip, shoulder, and ulna head arthroplasties found no impact on clinical outcome or increased risk of aseptic loosening of the implant. ${ }^{6,13,19,21,23,26}$ Twenty-three patients were followed after a Herbert ulna prosthesis for 11 years and no progress of bone resorption beneath the collar was found compared to the early follow-up, indicating that the bone remodeling process remains stable after the first year. ${ }^{13}$

If stress shielding may be less of a problem in ulna head replacement, the DRUJ stability is important. The partial ulna head arthroplasty was developed to preserve the native soft tissue restraints of the DRUJ, in contrast to the total ulna head arthroplasty, in which the intrinsic ligaments are sacrificed. ${ }^{11}$ By speculation, when resecting the stabilizing ligaments, the sagittal displacement between the distal ulna and radius increases. The DRUJ capsule becomes wider, and a larger part of the distal ulna collar will become intraarticular, within the capsule. The ulna collar potentially becomes exposed to fluctuating fluid pressure known to cause bone resorption, ${ }^{27}$ which could pose an explanation to the observed resorption below the prosthetic head.

It is also possible that a relative DRUJ instability after ulna head replacement alters the mechanical load of the joint and that that stress shielding beneath the collar could be reduced with a partial ulna head design, due to the more stable and physiological DRUJ loading. We did not examine the patients in our cohort regarding clinical DRUJ stability, but we found no difference regarding the radiological stability between the two prosthetic designs, nor did we find any relationship between dorsal instability and bone resorption at 1 year in the regression analysis. However, DRUJ stability is a dynamic phenomenon that is not assessed adequately by static radiographs. Future studies of a potential relation between DRUJ stability and bone resorption in total and partial ulna head prothesis designs are thus needed.

Finally, patients with RA are more prone to progressive bone loss than patients with OA, due to the disease itself and medication. This might be a concern after arthroplasty in patients with RA, regardless of implant type. ${ }^{28,29}$ In our cohort, the partial ulna head prothesis was mainly inserted in patients with RA and since bone resorption was more pronounced after total ulna head prothesis, this phenomenon seemed to be more influenced by the concept and design of the prothesis rather than by the underlying diagnosis.

\section{Conclusion}

Early stress shielding and subcapital bone resorption are common after ulna head replacements. The design and concept of the prothesis are probably important factors for the development of this phenomenon. Larger studies with long-term follow-up are needed to better understand the scope of periprosthetic stress shielding in the DRUJ, with special attention to its functional implications and the risk of implant failures.

Ethical Review Committee Statement

The study was approved by Lund University Ethical Review Board, Sweden No. 2015/110 and No. 2015/121.

\section{Location}

The work was performed at the Department of Translational Medicine and the Department of Clinical Sciences, both at Lund University, Lund, Sweden

\section{Funding}

This research was supported by R\&D grant from Region Skåne, Sweden.

\section{Conflict of Interest}

M.T. is design surgeon (First Choice Partial Ulnar Head Replacement, Integra LifeSciences, $\mathrm{NJ}$ ) and have received royalties from Integra. E.B. and A.A. have no conflict of interest.

\section{Acknowledgments}

The authors thank Linnea Arvidsson for help with the schematic drawings.

\section{References}

1 Moulton LS, Giddins GEB. Distal radio-ulnar implant arthroplasty: a systematic review. J Hand Surg Eur Vol 2017;42(08): 827-838 
2 Warwick D, Shyamalan G, Balabanidou E. Indications and early to mid-term results of ulnar head replacement. Ann R Coll Surg Engl 2013;95(06):427-432

3 Kakar S, Swann RP, Perry KI, Wood-Wentz CM, Shin AY, Moran SL. Functional and radiographic outcomes following distal ulna implant arthroplasty. J Hand Surg Am 2012;37(07):1364-1371

4 Willis AA, Berger RA, Cooney WP III. Arthroplasty of the distal radioulnar joint using a new ulnar head endoprosthesis: preliminary report. J Hand Surg Am 2007;32(02):177-189

5 Galvis EJ, Pessa J, Scheker LR. Total joint arthroplasty of the distal radioulnar joint for rheumatoid arthritis. J Hand Surg Am 2014;39 (09):1699-1704

6 Axelsson P, Sollerman C, Kärrholm J. Ulnar head replacement: 21 cases; mean follow-up, 7.5 years. J Hand Surg Am 2015;40(09):1731-1738

7 Sabo MT, Talwalkar S, Hayton M, Watts A, Trail IA, Stanley JK. Intermediate outcomes of ulnar head arthroplasty. J Hand Surg Am 2014;39(12):2405-11.e1, e1

8 Baring TK, Popat R, Abdelwahab A, Ferris B. Short- to mid-term results of ulna head replacement as both a primary and revision implant. J Clin Orthop Trauma 2016;7(04):292-295

9 Calcagni M, Giesen T. Distal radioulnar joint arthroplasty with implants: a systematic review. EFORT Open Rev 2017;1(05):191-196

10 Garcia-Elias M. Failed ulnar head resection: prevention and treatment. J Hand Surg [Br] 2002;27(05):470-480

11 Kopylov P, Tägil M. Distal radioulnar joint replacement. Tech Hand Up Extrem Surg 2007;11(01):109-114

12 Garcia-Elias M. Eclypse: partial ulnar head replacement for the isolated distal radio-ulnar joint arthrosis. Tech Hand Up Extrem Surg 2007;11(01):121-128

13 van Schoonhoven J, Fernandez DL, Bowers WH, Herbert TJ. Salvage of failed resection arthroplasties of the distal radioulnar joint using a new ulnar head prosthesis. J Hand Surg Am 2000;25(03):438-446

14 Masaoka S, Longsworth SH, Werner FW, Short WH, Green JK. Biomechanical analysis of two ulnar head prostheses. J Hand Surg Am 2002;27(05):845-853

15 Hagert CG. Distal radius fracture and the distal radioulnar jointanatomical considerations. Handchir Mikrochir Plast Chir 1994; 26(01):22-26

16 Frost HM. Wolff's Law and bone's structural adaptations to mechanical usage: an overview for clinicians. Angle Orthod 1994;64(03):175-188
17 Engh CA, McGovern TF, Bobyn JD, Harris WH. A quantitative evaluation of periprosthetic bone-remodeling after cementless total hip arthroplasty. J Bone Joint Surg Am 1992;74(07): 1009-1020

18 Frost HM. Bone "mass" and the "mechanostat": a proposal. Anat Rec 1987;219(01):1-9

19 Bauer TW, Schils J. The pathology of total joint arthroplasty.II. Mechanisms of implant failure. Skeletal Radiol 1999;28(09): 483-497

20 Denard PJ, Raiss P, Gobezie R, Edwards TB, Lederman E. Stress shielding of the humerus in press-fit anatomic shoulder arthroplasty: review and recommendations for evaluation. J Shoulder Elbow Surg 2018;27(06):1139-1147

21 Nagels J, Stokdijk M, Rozing PM. Stress shielding and bone resorption in shoulder arthroplasty. J Shoulder Elbow Surg 2003;12(01):35-39

22 Herbert TJ, van Schoonhoven J. Ulnar head replacement. Tech Hand Up Extrem Surg 2007;11(01):98-108

23 Herzberg G. Periprosthetic bone resorption and sigmoid notch erosion around ulnar head implants: a concern? Hand Clin 2010; 26(04):573-577

24 Adams BD, Gaffey JL. Non-constrained implant arthroplasty for the distal radioulnar joint. J Hand Surg Eur Vol 2017;42(04): 415-421

25 Park KS, Jin SY, Lim JH, Yoon TR. Long-term outcomes of cementless femoral stem revision with the Wagner cone prosthesis. J Orthop Surg Res 2021;16(01):375

26 DeVito P, Judd H, Malarkey A, et al. Medial calcar bone resorption after anatomic total shoulder arthroplasty: does it affect outcomes? J Shoulder Elbow Surg 2019;28(11): 2128-2138

27 Aspenberg P, van der Vis H. Fluid pressure may cause periprosthetic osteolysis. Particles are not the only thing. Acta Orthop Scand 1998;69(01):1-4

28 Jordan RW, Manoharan G, Van Liefland M, et al. Reliability of stemless shoulder arthroplasty in rheumatoid arthritis: observation of early lysis around the humeral component. Musculoskelet Surg 2021 Aug;105(02):139-148

29 Shim JH, Stavre Z, Gravallese EM. Bone loss in rheumatoid arthritis: basic mechanisms and clinical implications. Calcif Tissue Int 2018;102(05):533-546 